\title{
Breaking the link - A consideration of the pensions buy-out market in the United Kingdom following recent developments in the accounting and regulatory regime for the measurement and reporting of liabilities of defined benefit pension schemes
}

Received (in revised form): 12 September, 2007

\begin{abstract}
Alan Kirkpatrick
is a lecturer and financial management consultant. After obtaining primary and postgraduate degrees in economics from Durham University and Oxford University, he qualified as a chartered accountant in Ireland with a 'big 4' firm. He has held senior positions in treasury management and structured finance in financial institutions including London Forfaiting Company PLC, WestLB and Landesbank Baden-Württemberg, and has recently lectured to pension fund managers, trustees and accountants on the subject of pensions accounting and regulation.
\end{abstract}

\begin{abstract}
This paper considers how the pensions buy-out market in the United Kingdom might be affected by the amendment to Financial Reporting Standard 17 (FRS 17) in December 2006, the issue of a Reporting Statement 'Retirement Benefits - Disclosures' in January 2007 and the publication by The Pensions Regulator (TPR) of guidance on abandonment in May 2007. The amended version of FRS 17 and the Reporting Statement are responses to a more complicated pensions environment and they might help to bring: (1) wider recognition of the liability measurement issues and the size of the deficit problem; (2) increased confidence in measurement methods and the reporting regime; and (3) greater convergence of actuarial assumptions used by United Kingdom companies following increased disclosure and greater transparency in liability measurement. Greater transparency in reported information about defined benefit (DB) pension schemes may also help to stimulate the markets for buy-outs and other risk management solutions.

Pensions (2007) 12, 185-197. doi:10.1057/palgrave.pm.5950056
\end{abstract}

Keywords: amendment, disclosures, recognition, measurement, convergence, transparency

\section{Background to the UK pensions environment}

\section{Legislation and regulation - A brief outline}

Since the early 1990s, the regulation of the UK pension industry has developed with the

Correspondence: Alan Kirkpatrick, Park House, Park Homer Road, Wimborne, Dorset, BH21 2SP

E-mail: AlanKpk@aol.com enactment of important laws. The Pensions Act 1995 required pension funds to offer guarantees ${ }^{1}$ to members including guaranteed minimum funding and indexation of benefits. The Pensions Act 2004 created $^{2}$ The Pensions Regulator ('TPR') and the Pension Protection Fund ('PPF'). TPR was given two major objectives of protecting the benefits of pension scheme members and reducing the risk of situations leading to PPF compensation claims. 
The PPF was established to pay compensation to members of defined benefit ('DB') schemes in the event of qualifying insolvency of the employer where scheme assets are insufficient to cover PPF levels of compensation. Members are not treated equally. Only members who are above normal pension age receive 100 per cent of their benefits. Other members receive 90 per cent of their benefits as set out in the 2004 Act. ${ }^{3}$ The annual 'compensation cap', ${ }^{4}$ which is

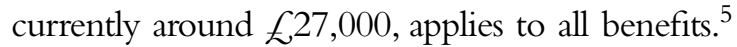
The PPF charges pension schemes a pension protection levy, which is similar to an insurance premium and is composed of a scheme-based levy and a risk-based levy. To calculate the risk-based pension levy, the PPF takes account of the scheme underfunding and completes a PPF valuation or 's179 valuation' named after section 179 of the 2004 Act, which sets out the provisions. ${ }^{6}$

\section{The problem of deficits}

DB schemes have come under increasing scrutiny by parties including the employer entities, pension scheme trustees and more recently by TPR due to the tendency of scheme liabilities to grow to levels beyond the extent of scheme assets. The liabilities are the obligations to pay DBs based on final salaries and are subject to risk factors such as longevity after retirement. The scheme assets comprise the investments required to fund the company's obligations and are subject to risk factors such as economic or investment performance. The problem of pension scheme deficits is a concern at both corporate and national level. TPR and the PPF analysed a sample of DB schemes comprising around 85 per cent of the total private sector DB scheme membership and found that aggregate s179 deficits were $\mathcal{H}^{33.8 b n}$ at 31st March, 2006 for the schemes in the sample and estimated that the figure was around $\mathcal{E}^{3} 3 \mathrm{bn}$ when the sample data were extrapolated to the population. ${ }^{7}$ The estimate by TPR and the PPF of the aggregate deficit of the sample schemes on an FRS 17 basis

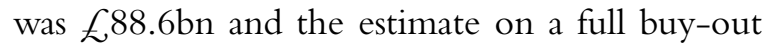
basis was $\mathcal{L}_{4} 40 \mathrm{bn}$ - using data only from schemes in deficit, the FRS 17 and full buy-out

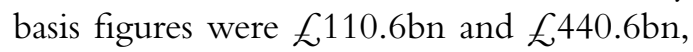
respectively. The data are summarised in Table 1.
The problem of deficits has led many employer companies to close DB schemes to new entrants and, increasingly, to future benefit accrual. A report by the Office of National Statistics states that between 1997 and 2005, there was a decline in employee membership of DB pension schemes expressed as a percentage of the private sector workforce, from 46 to 35 per cent while over the same period membership of defined contribution schemes increased from 10 to 15 per cent. ${ }^{8}$ Even if companies attempt to contain liabilities by limiting the growth of DB scheme membership and perhaps, by tighter control of the rate of salary increases, considerable uncertainty remains about the true extent of DB scheme liabilities.

\section{Longevity}

The upward trend in longevity of pensioners has been a major factor in the rise of the liabilities that have in many cases, put schemes into deficit. It is useful to look at some of the statistical sources in assessing the longevity assumptions that actuaries have incorporated into the measurement of the scheme liabilities. Information about historic life expectancy trends in the UK is available on the Government Actuary's Department (GAD) website, ${ }^{9}$ although the responsibility for publishing life tables in the future has now passed to the National Statistics Office (NSO). The life expectancy tables for the UK compiled by the $\mathrm{NSO}^{10}$ show that in 1981 a 60-year-old man could have been expected to live for 16.3 further years but in 2004 the figure was 20.5 years - the corresponding figures for females at 60 show life expectancy of 20.8 years (1981) and 23.6 years (2004). The NSO life expectancy tables also indicate increases for other age groups for both males and females, for example a 70-year-old man would have been expected to live for 10.1 more years in 1981 but 13.1 more years in 2004 - the corresponding figures for females show life expectancy of 13.3 years (1981) and 15.5 years (2004).

More detailed statistics produced by the NSO are shown in Table 2.

It should be noted that the figures shown in Table 2 are significantly lower than the figures in two standard actuarial tables commonly used for 
Table 1: Overall funding levels for a sample of DB schemes in the UK

\begin{tabular}{|c|c|c|c|}
\hline & s179 & FRS 17 & Full buy-out \\
\hline $\begin{array}{l}\text { Total schemes } \\
\text { (about } 85 \% \text { of } \\
\text { private sector) }\end{array}$ & 5,772 & 5,772 & 5,772 \\
\hline Total assets £bn & 635.5 & 635.5 & 635.5 \\
\hline Total liabilities £bn & 669.2 & 724.0 & $1,075.8$ \\
\hline $\begin{array}{l}\text { Aggregate deficits } \\
£ b n\end{array}$ & -33.8 & -88.6 & -440.4 \\
\hline $\begin{array}{l}\text { Total deficits for } \\
\text { schemes in deficit } \\
\text { £bn }\end{array}$ & -76.3 & -110.6 & -440.6 \\
\hline $\begin{array}{l}\text { Total surpluses } \\
\text { for schemes in } \\
\text { surplus } £ b n\end{array}$ & 42.6 & 22.1 & 0.3 \\
\hline
\end{tabular}

Source: The Pensions Regulator.

assessing mortality in pension schemes: these are known as the 'PA92 tables' and the 'PA92 tables with medium cohort adjustment'. Lane et al. ${ }^{11}$ explain that: (1) the 'PA92' tables that were released in 1999 and are based on experience during 1991-4 included an allowance for future improvements in life expectancy; and (2) the 'PA92 tables with Medium Cohort Adjustment' make an adjustment based on more recent research that shows that certain people, in particular the cohort born between 1925 and 1945 (the 'medium cohort') were living much longer than expected.

The figures in Table 2 show the overall national average and general trend over time however, longevity assumptions for a specific workforce may take account of factors such as occupation, social background and geographical location as well as gender. The comparison of the figures in Table 3 shows a wide variation of life expectancy for a male at age 60 with the expected age at death ranging from 80 years to 87 years depending on which statistical source is used. This indicates how different assumptions of improvement rates may result in significant changes to fundamental actuarial inputs. Concerns have been expressed that even the PA92 tables adjusted for medium cohort may significantly underestimate the extent of longevity improvements that are occurring. For this reason, the longevity tables that form the basis of assumptions are the subject of continuing review
Table 2: Life expectancy in the UK ${ }^{\mathrm{a}}$

\begin{tabular}{|c|c|c|c|c|c|c|}
\hline \multirow[b]{3}{*}{ Year $(Y)$} & \multicolumn{3}{|c|}{ Males } & \multicolumn{3}{|c|}{ Females } \\
\hline & \multicolumn{3}{|c|}{$\begin{array}{l}\text { Life expectancy } \\
\text { at age }(X)\end{array}$} & \multicolumn{3}{|c|}{$\begin{array}{l}\text { Life expectancy } \\
\text { at age }(X)\end{array}$} \\
\hline & 60 & 70 & 80 & 60 & 70 & 80 \\
\hline 2004 & 20.5 & 13.1 & 7.4 & 23.6 & 15.5 & 8.8 \\
\hline 2003 & 20.2 & 12.9 & 7.3 & 23.4 & 15.3 & 8.7 \\
\hline 2002 & 20.0 & 12.6 & 7.2 & 23.3 & 15.2 & 8.7 \\
\hline 2001 & 19.8 & 12.5 & 7.1 & 23.2 & 15.2 & 8.7 \\
\hline 2000 & 19.5 & 12.3 & 7.0 & 23.0 & 15.0 & 8.6 \\
\hline 1999 & 19.2 & 12.0 & 6.8 & 22.8 & 14.8 & 8.5 \\
\hline 1998 & 18.9 & 11.9 & 6.7 & 22.6 & 14.7 & 8.4 \\
\hline 1997 & 18.8 & 11.7 & 6.7 & 22.5 & 14.6 & 8.4 \\
\hline 1996 & 18.5 & 11.6 & 6.6 & 22.3 & 14.5 & 8.3 \\
\hline 1991 & 17.7 & 11.1 & 6.4 & 21.9 & 14.3 & 8.2 \\
\hline 1986 & 16.8 & 10.5 & 6.0 & 21.2 & 13.8 & 7.8 \\
\hline 1981 & 16.3 & 10.1 & 5.8 & 20.8 & 13.3 & 7.5 \\
\hline
\end{tabular}

Source: Compiled from UK National Statistics Office 'Population Trends'.

'Period expectation of life at age ' $X$ ' in year ' $Y$ '.

and analysis by the actuarial profession through the Continuous Mortality Investigation (CMI). In 2007, the CMI has been trying to consolidate a 'library' of Mortality Projections and build on the work carried out on the ' 00 ' Series tables by inter alia developing sets of projections that can be used as benchmarks. ${ }^{12}$

The PA92 tables even when adjusted for the medium cohort also require further analysis and adapting to particular cases. Predicting the future trend in practice is a very complex task. It is necessary to perform detailed analysis of possible scenarios and try to estimate the probability of certain outcomes. This analysis is often shown in the form of 'forecasting funnels', referring to the pattern of line graphs representing the upper and lower percentiles of the probability distributions of possible future longevity outcomes for different cohorts - greater uncertainty will result in a wider forecasting funnel or a 'funnel of uncertainty'. ${ }^{13}$ Uncertainty arises for example, from risks of incorrect modelling of probability distributions, an insufficient data set, trend changes with wealth and health effects, and random chance variations.

Uncertainty about future longevity also arises from very different views of health factors, in particular the alternative expert views about the physiological limits of aging, the impact of 
Table 3: Life expectancy ${ }^{\mathrm{a}}$ of males at age 60 - Different sources compared

\begin{tabular}{ll}
\hline NSO (2004) tables & 80 years \\
PA92 tables & 84 years \\
PA92 tables with 'medium cohort' & 87 years \\
\hline
\end{tabular}

Source: Adapted from National Statistics Office (Population Trends) and Lane, Clark and Peacock. ${ }^{11}$

${ }^{a}$ Expected age at death rounded to the nearest age in years.

behavioural factors (exercise and diet) and medical advances. The Pensions Commission has referred to the debate ${ }^{14}$ between experts such as Professor Jay Olshansky of the University of Illinois at Chicago School of Public Health and Professor James Vaupel from The Max Planck Institute for Demographic (Studies) in Rostock, Germany. On the one hand, experts such as Professor Olshansky suggest that life expectancy could level off or decrease in the 21 st century due to factors such as the rise in obesity levels and the potential effects of infectious diseases while there is an absolute limit to the rise in life expectancy due to biological constraints. On the other hand, another group of experts including Professor James Vaupel suggest that life expectancy is set to continue at a rapid rate due to medical advances and other factors.

\section{Other causes of DB pension scheme deficits}

Clark and Monk, ${ }^{15}$ in a survey focusing upon UK and US private employer-sponsored plans in 2001 and 2002, describe two 'perfect storms': perfect storm I of low asset returns and interest rates that had 'devastating effects on pension plans: as lower discount rates increased the value of expected liabilities (but) the assets intended to cover these liabilities fell dramatically in value'; and, perfect storm II, a 'regulatory perfect storm' set off by the first perfect storm when 'in a short period, UK pension funding regulations went from lax to strict, thereby exacerbating firms' funding schedules'. Clark and Monk ${ }^{15}$ have astutely observed how the removal, by the UK government, of the pension funds' dividend tax credit has been especially counterproductive: 'Paradoxically, the 1997 change in Treasury regulations denying pension funds' dividend tax credit has dramatically adversely affected plan funding schedules'. Most of the ten-year period after 1997 was characterised by pension scheme deficits for many companies and even though there were reports in the middle of 2007 that the 200 largest pension schemes had moved into surplus, ${ }^{16}$ this was largely due to rising bond yields and a continuing strong run of rising share prices. Short-term fluctuations in investment values are inevitable and the focus may be on longer term investment performance, yet the volatility in the equity markets in the UK for example in 2007 will probably have reminded many companies and trustees of the sensitivity of pension schemes to the performance of their investment portfolios.

Another problem arises from the indexation of pension benefits, which is a particular characteristic of DB schemes in the UK. Clark and Monk refer to the work of Feldstein ${ }^{17}$ according to whom switching to a fully indexed pension for a male aged 65 years (assuming 6 per cent per annum) from a nominal pension benefit would increase the pension cost by 50 per cent. Indexation even when subject to a capped rate is a particular problem when combined with the effect of salary growth and the consequently high final salary levels that are used as the basis for calculating the pension benefits.

Challenges have emerged in the way pension scheme assets and liabilities have to be recognised and measured as part of the statutory financial reporting process of employer businesses. When analysing the statistical output it is important to consider the measurement process itself as well as inputs to that process.

\section{Problems of measurement - Accounting for liabilities (FRS 17 and IAS 19)}

\section{Disclosure levels and the international convergence of accounting standards} In the United Kingdom, the two accounting standards of particular relevance to the matter of accounting for retirement benefits are: the Financial Reporting Standard 'FRS 17' issued by the UK-based Accounting Standards Board (ASB) 
and the international accounting standard 'IAS 19' issued by the International Accounting Standards Board (IASB). In December 2006, the ASB published an Amendment to FRS 17 which reflected a move towards greater convergence with the IAS 19 requirements. ${ }^{18}$

Very shortly after that, in January 2007, the ASB published a Reporting Statement, 'Retirement Benefits - Disclosures', setting out additional disclosures ${ }^{19}$ that complement the disclosure requirements of FRS 17 - unlike FRS 17 it is a best practice guide and is not mandatory.

The ASB has acknowledged that the FRS 17 Amendment is the result of a short-term project as only the first stage of a longer term research project to consider the prospect of full international pensions accounting convergence. ${ }^{20}$ Nevertheless, the Amendment to FRS 17 added some important disclosure requirements and removed some others - the net effect is a significant increase in required reporting information. Major additional disclosures ${ }^{21}$ highlighted by the ASB include:

- information that enables users of the financial statements to evaluate the nature of the entity's participation in DB schemes and the financial effects of changes in those schemes (previously only the 'nature of schemes' needed to be disclosed);

- the principal actuarial assumptions used as at the balance sheet date (previously only the main financial assumptions required disclosure);

- an analysis of the opening and closing scheme liabilities and scheme assets showing separately if applicable the movements in scheme assets and liabilities; and

- an analysis of scheme liabilities into amounts arising from schemes that are wholly unfunded and amounts arising from schemes that are wholly or partly funded.

Of the possible methods of measuring or valuing the assets and liabilities of pension schemes the most important bases to consider are the traditional FRS 17 basis and the buy-out basis.
For financial reporting purposes in the UK, the amended FRS 17 basis is the most relevant approach. FRS 17 requires disclosure for the current and the previous four accounting periods $^{22}$ of:

- pension fund surpluses or deficits (more usually) of the employer companies;

- scheme assets measured at fair value, which is for example open market value for property and the current bid price for quoted securities;

- the present value of the DB obligation (scheme liabilities); and

- the experience adjustments expressed either

(i) as an amount or

(ii) as a percentage of the scheme assets at the balance sheet date.

\section{The projected unit method}

FRS 17 recommends that DB scheme liabilities should be measured on an actuarial basis using the 'Projected Unit Method'. ${ }^{23}$ Before describing the Projected Unit Method, it will be useful to distinguish between two categories of actuarial methods referred to in FRS 17 for valuing DB liabilities:

- Accrued benefits methods

- Prospective benefits methods.

An accrued benefits method involves allocating an amount representing a share of the eventual undiscounted cost to each period. The liability arising from the costs to date is then discounted and the discount unwinds over the employee's service life. This means that the cost will be higher at the end of the employee's service life than at the beginning as the discounting effect will reduce as the employee approaches retirement.

A prospective benefits method involves spreading the total cost including all the interest that will accrue, evenly over the employee's service life. It is argued in FRS 17 that such a method does not represent the economic reality based on the concept of the time value of money and that the cost of providing a DB pension 
increases as the retirement date approaches so it is necessary to use an accrued benefits method.

The projected unit method is an accrued benefits valuation method in which the scheme liabilities make allowance for projected earnings. In such a valuation method, the scheme liabilities at the valuation date relate to: the benefits for pensioners and deferred pensioners (who are individuals who have ceased to be active members but are entitled to benefits payable at a later date) and their dependants, allowing for future increases, and the accrued benefits for members in service on the valuation date. FRS 17 also refers to the matter of estimating future retirement benefits other than pensions, for example, retirement healthcare liabilities for which it will be necessary to account for expected changes in medical care costs.

\section{The discount rate}

The ASB expresses the belief that DB scheme liabilities should be discounted at a rate that reflects the time value of money and the characteristics of the liability. ${ }^{24}$ FRS 17 recommends that the discount rate should be assumed to be the current rate of return on a high-quality corporate bond of equivalent currency and term to the scheme liabilities - a 'high-quality corporate bond' is described as a bond that has been rated at the level of AA or equivalent status. ${ }^{25}$ It is a reasonable question to ask what happens if there is no liquid market in bonds of the described type or duration. The suggestion in FRS 17 is that a reasonable proxy may be government bonds plus a margin for assumed risk spreads derived from global bond markets. There has been some debate about the appropriateness of this approach to determining the discount rate and the difficulty and subjectivity of estimating the appropriate premium over the risk-free rate. ${ }^{26}$

\section{Possibility of using the buy-out basis}

The original FRS 17 acknowledged that ideally under a 'market value approach', the scheme liabilities would be measured at market value to provide a 'fair value', similarly to the scheme assets. The explanation for FRS 17 requiring the use of a different method is that 'there is no active market for most defined benefit scheme liabilities'. ${ }^{27}$ Nevertheless, it should be pointed out that much has changed in terms of the current and the prospective market since the first FRS 17 was published in November 2000. It was in the draft Reporting Statement that the ASB included a recommendation to disclose the scheme liabilities calculated on a buy-out basis.

Opinions were invited and received from interested parties including the major accounting bodies and their members, the Actuarial Profession and the British Bankers' Association. There were a number of objections to the use of the buy-out approach, mainly falling into three broad categories. The first related to concerns that the buy-out approach might be irrelevant or even misleading, for example the Actuarial Profession ${ }^{28}$ mentioned in its letter to the ASB that the buyout market is not very transparent so that it would be difficult for entities and their advisers to form an accurate view of the buy-out cost that would be agreed in the event of a transaction and the disclosed buy-out costs would therefore be very approximate. The Actuarial Profession also stated in the same letter that it would be necessary to take a view on what information to disclose for the largest schemes with liabilities beyond the capacity of the bulk annuity market. The second objection was on the grounds of consistency, for example, the Institute of Chartered Accountants in England and Wales $(\text { ICAEW })^{29}$ argued that it would be inconsistent in principle with the going concern basis and would be unlikely to be a true 'fair value'. It is relevant to consider the concept of 'fair value' that is generally defined in International Financial Reporting Standards ('IFRS's) as 'the amount for which an asset could be exchanged, or a liability settled, between knowledgeable, willing parties in an arm's length transaction'. ${ }^{30}$ With respect to liabilities, the IFRS definition differs from the approach under for example, US accounting, in which the definition of 'fair value' rests on the notion that the liability is 'transferred' ${ }^{31}$ rather than settled. Recent proposals by the IASB seem to favour using 'exit values' to determine 'fair 
value' for insurance contracts and the ASB has noted in a Briefing Paper (July 2007) ${ }^{32}$ responding to the IASB position, that there are certain similarities between insurance and pensions liabilities. The Actuarial Profession and the British Bankers Association ${ }^{33}$ also expressed concerns that the use of the buy-out approach may be inconsistent with the going concern principles and asked why retirement benefits should be the single area of accounting where such a 'break up value' is disclosed. The third objection was that the buy-out approach could result in significant costs due to the greater disclosures proposed in the amended FRS 17 and the Reporting Statement, which it was pointed out, would be particularly heavy for overseas schemes and disproportionately burdensome for medium-sized companies. Organisations raising concerns over costs included the ICAEW, the Actuarial Profession and the British Bankers' Association. The Actuarial Profession in its letter to the ASB (referred to earlier) stated that significant costs could arise due to the need to calculate and disclose the buy-out cost, especially when that cost calculated for the scheme's own requirements would probably not be calculated as at the same date as required for the entity's accounting year-end date.

After further discussion, the ASB deferred a decision on recommending disclosure in the Reporting Statement of a buy-out amount of a pension scheme. ${ }^{34} \mathrm{~A}$ buy-out basis might be expected to result in higher estimates of liabilities than the FRS 17 basis and it may also be argued that it would be reasonable and prudent to disclose liabilities on a buy-out basis if business entities are already in possession of such a valuation performed by a third party. The ASB was still interested in keeping open the option of disclosure of a valuation on a buy-out basis if such a valuation existed. Therefore, included within the additional disclosures set out in the Reporting Statement, 'Retirement Benefits Disclosures' in January 2007 is the very significant one relating to the use of buy-out values as follows: "Where the cost of buying out benefits is made available to trustees (managers) and/or members of DB schemes it is recommended that the financial statements also disclose the cost of buying out benefits'. ${ }^{35}$ It is worth stressing that the Reporting Statement referred to here is a best practice guide and is not mandatory so companies are still not legally required to obtain a buy-out valuation. ${ }^{36}$

\section{Why liabilities are higher on a buy-out basis than on the FRS 17 basis}

It is to be expected that a buy-out transaction will involve significant costs due to the need for skilled analysis, careful structuring, considerable due diligence, legal documentation and the assumption of open-ended risk relating to the pension scheme obligations. It has been suggested that the difference between the buy-out valuation and FRS 17 valuation of DB pension scheme liabilities may be around 30 per cent with components of the uplift perhaps comprising the following: ${ }^{37}$ adjustment to incorporate the best estimate of longevity (10 per cent); expenses relating to administration and investment (4 per cent); market adjustments for inflation and the discount rate ( 2 per cent); and the buy-out premium (14 per cent).

\section{Inclusion of actuarial assumptions and possible convergence}

Under the amended FRS 17, the actuarial assumptions that include mortality, inflation, salary/pension increases, returns on equities and the discount rate will have to be disclosed. ${ }^{38}$ The assumptions have a crucial impact on valuation and it is significant and perhaps of some concern that a report by the Financial Reporting Review Panel $^{39}$ has revealed considerable variations in assumptions - especially longevity that has a major impact on valuation. Lane et al. ${ }^{11}$ carried out a survey of life expectancies assumed by FTSE 100 companies at the December 2005 year end and found that out of 33 companies providing sufficient information, the assumptions of life expectancy varied widely for retirees at age 60, as follows: three companies assumed life expectancy of 82 years or less; two companies assumed 87 years or more; and the rest were in the range of 83-86 years. Lane et al. found that the average discount rate used by the companies 
in its survey fell from 5.32 per cent in December 2004 to 4.77 per cent in December 2005, reflecting significant falls in bond yields, which they estimate could have added nearly 10 per cent to companies' pension liabilities (equivalent to increasing the aggregate deficits by about f30bn) - significantly, the difference between the highest and lowest discount rate used fell from 0.65 to 0.25 per cent. Auditors will have been looking more closely at the discount rates as pension deficits are appearing in the financial statements. The reduction in the range of discount rates used seems to support the view that greater disclosure and audit scrutiny may result in more convergence of the input assumptions of different entities.

The FRS 17 Amendment takes effect for accounting periods beginning on or after 6th April, 2007, although early adoption is encouraged. ${ }^{40}$ Therefore, it may be possible to observe the effects on financial reporting before 2008. It will be interesting to see whether longevity assumptions begin to converge as greater transparency exposes reporting companies to more scrutiny and questioning by investors and other stakeholders.

\section{Levels of disclosure - Actuarial valuations and reports}

Pension schemes are already required by law to obtain quite a significant amount of actuarial information. Actuarial valuations and reports play an important part in the analysis of the financial situation and decision process especially when there is a proposed restructuring of the relationship between the pension scheme and its sponsor. The Pensions Act 2004 requires that the trustees or managers must obtain actuarial valuations at intervals of not more than one year or, if they obtain actuarial reports for the intervening years, at intervals of not more than three years.

An 'actuarial valuation' is defined in the 2004 Act as '.... a written report, prepared and signed by the actuary, valuing the scheme's assets and calculating its technical provisions'. ${ }^{41}$ An 'actuarial report' is defined as '.... a written report, prepared and signed by the actuary, on developments affecting the scheme's technical provisions since the last actuarial valuation was prepared..... ${ }^{42} \mathrm{~A}$ scheme's 'technical provisions' are defined in the 2004 Act as the amount required on an actuarial calculation, to make provision for the scheme's liabilities. $^{43}$

When presenting the draft FRS 17 amendment and Reporting Statement, the ASB expressed the view that the proposals would in the main lead to disclosures of information that an entity already had available so that additional costs should be minimal. The Actuarial Profession in its letter to the ASB as referred to earlier, raised concerns about the costs of certain additional disclosures including the buy-out cost already discussed here. This is a reminder of a key issue in financial reporting that is relevant to many areas of accounting, not just pensions - the need to achieve the appropriate level of detail for disclosures. On the one hand, too little detail may leave users of accounting information in a position where they cannot understand or analyse that information. On the other hand, too much detail may confuse or mislead users of accounting information. There is for example, the danger of losing crucial nuances when attempting to translate the legal language of voluminous documentation into plain English and at the same time or alternatively, summarising that information.

\section{The justification for the buy-out option}

\section{The extent of ongoing problems of deficits}

Pension fund deficits are associated with a number of problems. In the first place, they usually result in the reallocation of at least some financial resources away from the productive operations of the business to permit investment in pension fund assets. This may result in such a reduction in capital investment that the competitive position of the business is weakened. Secondly, valuable management time is inevitably required to consider possible solutions to any deficit problem. Thirdly, measurement difficulties and market uncertainty result in volatility in the levels of pension fund deficits as both pension fund assets and liabilities fluctuate. Fourthly, 
particularly for companies with shares listed on a stock exchange, large or increasing pension fund deficits have a negative impact on the corporate image, workforce confidence and investor perception. These are some of the reasons for considering the buy-out option, but it is important to say that this discussion does not expect to provide an exhaustive list of possible problems associated with pension fund deficits.

\section{The search for a complete 'nonrecourse' solution and other options}

The available options may be considered in terms of the liability remaining with the sponsoring employer entity. Three levels of recourse are nonrecourse, limited recourse and full recourse. Nonrecourse options such as the full buy-out leave the employer business with no ongoing liabilities to the pension scheme or its members. The nonrecourse result is therefore, likely to be the preferred position but there is an inevitable trade-off between the amount of risk retained and the price. It is for this reason that a market for limited recourse solutions has developed. Limited recourse options include partial buy-outs, deferred buy-outs, and other forms of restructuring and risk management options. Partial buy-outs provide useful structural options and flexibility by enabling employer entities to be selective in determining which groups of scheme membership obligations should be bought out. A limited recourse solution by its nature does not remove all the liabilities from the balance sheet of the sponsoring employer, but it may be a step towards breaking the link to become nonrecourse after an agreed period. Deferred buy-outs may be structured with a phased approach to the transfer of liabilities from the employer entity to the acquiring entity. The full recourse options maintain the full link with the pension scheme perhaps by taking no action at all or merely transferring certain administrative functions to a servicing business such as an insurer.

\section{Considering the shorter term costs and potential longer term gains}

The buy-out option will usually result in a significant cost to the employer entity and in some cases management may conclude that the level of the buy-out cost is simply too high to justify. In view of the problems of pension fund deficits it is, however, understandable when companies and employer businesses consider breaking the link with the pension schemes in order to remove the ongoing longevity and investment risk. Before deciding whether or not a buy-out transaction is justified, the boards and executive management teams of employer companies must perform a full cost benefit analysis that examines not only the liabilities but also the structure of the scheme asset portfolio, investment policy and future viability of the pension scheme. Sponsoring business entities and scheme trustees will be expected to consider the detailed terms including pricing of the buy-out, the legal requirements, regulatory issues and the availability of other competing restructuring and risk management options.

\section{Other restructuring and risk management options}

\section{Types of risk protection}

Risk management options have been developed to provide longevity protection and investment risk protection. The extent of protection against each type of risk depends on the nature of the risk management solutions. Mortality bonds for example, provide more longevity protection than many other forms. Liability driven investment structures are designed to provide cash flow matching and aim to ensure more investment protection than many of the other forms of risk management. Insurers are able to offer full scheme annuitisation structures to provide longevity protection and investment protection. Other structures offering longevity and investment protection include structured buy-outs, partial scheme annuitisations and refundable buy-outs.

\section{Attractions of risk management options and market prospects}

Restructuring options that do not break the link with the pension scheme cannot be expected to provide the level of risk protection offered by the full buy-out — in essence, they provide a degree 
of risk reduction but not complete risk removal. Yet they are likely to be more affordable than the full buy-out option, particularly for business entities with very large pension scheme liabilities and deficits. The main providers of full buy-out services are also usually participants in the market for deferred buy-outs and other risk management solutions.

\section{TPR's impact}

\section{Guidance document}

In May 2007 TPR produced a guidance document entitled 'Abandonment of defined benefit pension schemes' (Abandonment Guidance) that may be relevant to potential buyout transactions depending on the nature of the acquiring entity. ${ }^{44}$ 'Abandonment of a pension scheme' is defined as a situation '..where the sponsoring employer severs its link with the scheme without providing the scheme with sufficient funds or assets to compensate for losing the ongoing support of its employer'.

\section{Trustee responsibilities}

TPR stresses that trustees have a significant duty of care when presented with proposed restructuring or disposal arrangements. The Abandonment Guidance states that TPR expects trustees' starting point to be that any arrangement that breaks the link with the existing employer may not be in members' interests unless the full section 75 debt $^{45}$ (the full amount necessary to insure members' benefits with a regulated insurer) is paid or unless the scheme remains supported by an employer of substance and is suitably compensated for any change in the employer's covenant.

\section{Substance over form}

TPR makes it clear that the Abandonment Guidance does not impose fixed rules and any proposal or arrangement must be considered on 'its individual merits' so that a review of the commercial substance rather than merely the legal form of the arrangement is considered to be the best approach to judging whether any arrangement constitutes abandonment. ${ }^{46}$ The Abandonment Guidance highlights some important responsibilities of trustees such as the performance of rigorous due diligence including analysis of the security of a proposed arrangement to make sure that the proposed arrangement is in members' best interests. ${ }^{47}$ Financial institutions such as Financial Services Authority (FSA) regulated insurance companies have been the major participants in the buy-out market and this is likely to continue in view of the legal and regulatory conditions that have been imposed to support members' interests. FSA regulated insurers are subject to continuous monitoring of capital levels and standards of expertise.

\section{Experience up to mid-2007 and market expectations}

\section{The players in the UK buy-out market and the level of activity}

The earliest participants in the UK pensions buyout market starting perhaps as far back as the 1980s were Legal \& General and Prudential. Since 2005 there has been a significant increase in the number of participants who have anticipated a growth in demand for buy-out transactions. Financial institutions known to have established pension buy-out activities include Aegon UBS, AIG, AVIVA, Canada Life, Citigroup, Goldman Sachs, Lucida, Paternoster, Pension Insurance Corporation, Sun Capital, Swiss Re, Synesis Life and XL Re. The size of the UK bulk DB scheme market has been estimated to be around $\mathcal{E} 800 \mathrm{bn}$, split into approximately $\mathcal{E}_{4} 400 \mathrm{bn}$ of deferred annuities and $\mathcal{E} 400 \mathrm{bn}$ pensions in payment, yet buy-outs transacted have amounted to only about $\mathcal{E} 10 \mathrm{bn}{ }^{48}$

\section{Possible future trend}

Estimating the possible future trend in demand is certainly important for market participants both those institutions that are already active and those that are budgeting capital allocations to potential buy-out or restructuring transactions. One of the less optimistic commentators is Aon Consulting Limited, which published research in April 2007 in which it stated that of its sample of 150 UK companies operating DB schemes only 10 per cent expect to remove their pension 
scheme liabilities within three years. ${ }^{49}$

Nevertheless, as a senior Aon Consulting researcher has observed, sponsors are interested in minimising or reducing the effect of pension schemes on their financial reports. ${ }^{50}$

Prospects for the buy-out market are likely to depend on a large number of factors including price, longevity increases, investment performance and macro-economic developments including interest rate policy. Evidence that the rate of increase in longevity is at the higher end of expectations may prompt employer entities that can afford to finance buy-outs of their pension schemes to do so rather than risk the costs rising out of reach in the future. It is also important to consider whether other restructuring and risk management options complement or compete with buy-outs.

\section{Competing products or steps to buy-out?}

On the one hand, the other restructuring and risk management products potentially compete against the buy-out approach. On the other hand, the alternative products may provide useful steps to ultimate buy-out. The due diligence and analysis required in the buy-out of larger schemes is necessarily a time-consuming exercise. Limited recourse structures that may be more easily executed may also lead logically to full buy-out transactions. Furthermore, the development of a market in limited recourse products may well bring further cost savings for scheme sponsors as competition and volumes permit price reductions. A secondary market could perhaps emerge and develop on a global scale if appropriately regulated financial institutions could anticipate sufficient liquidity in limited and full recourse packaged pension schemes.

\section{The future}

Increased transparency in financial reporting of pension scheme assets and liabilities is highly desirable. FRS 17 has been amended as a first stage in improving the financial reporting of retirement benefits and it is hoped that this may permit users to understand the assumptions made in calculating the figures. Greater disclosure of pension scheme obligations may help to highlight the problems faced by employer entities and force them to take action that might otherwise be deferred to the possible detriment of the longer term interests of stakeholders including shareholders and the pension scheme members. Much work remains to be carried out to try to overcome the problems of measurement and the resulting relatively low confidence of users of financial information about pension scheme liabilities. The ASB has confirmed that there will be further development of FRS 17 as part of an ongoing project. There is a need for and likelihood of extensive discussions and cooperation between the accounting, actuarial and other interested professions.

If businesses react as expected and seek to address the ongoing problems of large and fluctuating pension scheme deficits, they have a widening range of possible solutions provided by financial institutions that are in most cases financially strong and well regulated. The full buy-out option is the ultimate nonrecourse solution but cost is a key issue influencing the future growth of the market. Employer entities may consider partial or deferred buy-outs or other risk management solutions if full buy-outs are too expensive. Limited recourse options are flexible and may be applied to certain cohorts within a pension scheme.

There is continuing interest in pension scheme buy-outs whether in the form of full buy-outs or partial and deferred buy-outs. Large and fluctuating deficits are a major distraction for the management of sponsoring businesses in the UK, particularly those that are listed on the London Stock Exchange with a high public profile and perception concerns. The initial costs of particular buy-out structures should be considered in the light of projections of key factors such as longevity and pension fund investment performance. The choice between the different types of buy-out will depend on case-by-case assessments of the scheme memberships including specific workforce characteristics.

TPR is involved in the regulation and quality control of buy-out transactions and may be expected to intervene where there are situations constituting abandonment by employer entities. The prevalence of financially strong FSA 
regulated institutions in the buy-out market as well as the other risk management markets is a reflection of the market demands and regulative barriers in the market. The financial institutions already have significant amounts of funding available for limited recourse as well as nonrecourse solutions and there is clearly potential for both these markets to grow in the UK even if the level of transactions so far has been low relative to the extent of the $\mathrm{DB}$ pension schemes.

\section{References and Notes}

1 The Pensions Act 1995 - sections 51-55 (for Indexation) and sections 56-61 (for Minimum Funding requirement).

2 The Pensions Act 2004 Part 1 (sections 1-106) and Chapter 3 especially s173 for the PPF.

3 The Pensions Act 2004 Schedule 7 section 162 Pension Compensation Provisions.

4 The Pension Protection Fund (Compensation Cap Order) 2007.

5 PPF Compensation Cap Order 2007 — Explanatory Memorandum by the Department of Work and Pensions.

6 The Pensions Act 2004 section 179 Valuations to determine scheme underfunding.

7 The Pensions Regulator and Pension Protection Fund - The Purple Book DB Pensions Universe December 2006, page 28.

8 Office for National Statistics — Pension Trends - Private Pension Scheme Membership Highlights.

9 Government Actuary's Department - Interim Life Tables, 1980-82 to 2003-05.

10 The Office for National Statistics or ONS produces tables showing period expectation of life at birth and selected age.

11 Lane, Clark \& Peacock, Actuaries and Consultants (2006) Accounting for Pensions UK and Europe Annual Survey 2006, pages 25-26.

12 Continuous Mortality Investigation (18 July 2007) — Working paper 27 - The CMI 'library' of Mortality Projections, a consultation document requiring feedback from interested parties by 17th August, 2007.

13 I have used the term 'forecasting funnel(s)' to describe the shape made by line graphs of forecast data showing predicted trends for equal upside and downside probabilities - the concept is also often referred to by the phrase 'funnel of uncertainty' and also 'funnel of doubt' by Barrie and Hibbert see - http:// www.barrhibb.com/-docs/_pages/DB\%20pension\%20ALM\%20f yer.pdf.

14 The Pensions Commission (2005) — 'A New Pensions Settlement for the Twenty First Century' - Appendix E 'Uncertainties in life expectancy projections'.

15 Clark, G. L. and Monk, A. H. B. (2006) 'The "crisis" in defined benefit corporate pension liabilities Part I: Scope of the problem', Pensions, Vol. 12, pp. 46-47, 54.

16 Philip Aldrick, Daily Telegraph 19th May, 2007, 'Top 200 in surplus for first time in six years' referring to figures produced by Aon Consulting who also made cautionary remarks due to the volatile nature of the deficits.

17 Feldstein, M. (1981) 'Private pensions and inflation', The American Economic Review, Vol. 71, No. 2, pp. 424-428.
18 Accounting Standards Board FRS 17 Amendment December 2006.

19 Accounting Standards Board Reporting Statement: 'Retirement Benefits - Disclosures' - January 2007.

20 Accounting Standards Board FRS 17 Amendment December 2006, page 18 , paragraph $56 \mathrm{E}$.

21 Accounting Standards Board FRS 17 Amendment December 2006, pages 3-4.

22 Accounting Standards Board FRS 17 Amendment December 2006, page 13, new paragraph 77 (o) - shown in a different order in the text for emphasis.

23 Accounting Standards Board FRS 17 November 2000, pages 15-64.

24 Accounting Standards Board FRS 17 November 2000, page 61, Appendix IV, paragraphs 13-14.

25 Accounting Standards Board FRS 17 November 2000, page 19, paragraph 33 and page 64, Appendix IV, paragraph 21.

26 Accounting Standards Board FRS 17 November 2000, pages 61-64, Appendix IV, paragraphs 13-22.

27 Accounting Standards Board FRS 17 November 2000, page 59, Appendix IV, paragraph 11.

28 The Actuarial Profession (comprising the Faculty of Actuaries and the Institute of Actuaries) - response to the ASB Proposals to amend FRS 17 'Retirement Benefits', and to issue a new Reporting Standard 'Retirement Benefit — Disclosures' September 2006.

29 ICAEW July 2006 - ICAEW REP 50/06 Retirement Benefits 'Memorandum of comment submitted in July 2006 by the Institute of Chartered Accountants in England and Wales, in response to the Exposure Draft Proposed Amendment to FRS 17 "Retirement Benefits" and a draft Reporting Statement 'Retirement Benefits — Disclosures', published for comment by the Accounting Standards Board on 31st May, 2006.

30 International Accounting Standards Board - Discussion Paper, 'Fair Value Measurements Part 1: Invitation to comment and relevant IFRS guidance', November 2006, page 8, paragraph 10 see http://www.iasb.org/NR/rdonlyres/6C8AF291-EB14-403484F1-54305F72024D/0/DDFairValue.pdf.

31 SFAS 157, paragraph 5 defines 'fair value' as 'the price that would be received to sell an asset or paid to transfer a liability in an orderly transaction between market participants at the measurement date'.

32 Accounting Standards Board - ASB Briefing paper July 2007 on IASB proposals on Insurance Contracts - Implications for Other Business Sectors.

33 British Bankers' Association — Letter to ASB entitled 'Comments by the British Bankers' Association' 9 October 2006 - see http://www.bba.org.uk/bba/jsp/polopoly.jsp?d=155\&a=7712.

34 Accounting Standards Board - Minutes of a meeting in London on 19 October 2006 (Item number 4 on FRS Retirement Benefits) — see http://www.frc/images/uploaded/ documents/Minutes\%2019\%20October\%20061.pdf.

35 Accounting Standards Board Reporting Statement: Retirement Benefits - Disclosures January 2007, page 11, paragraph 17.

36 Accounting Standards Board Reporting Statement: Retirement Benefits - Disclosures January 2007, page 3, paragraph 1.

37 Synesis Life (June 2007) — example given by Jay Shah (Corporate Development Director) in his presentation entitled 'Advancements in new buy-out products' at the 'Pension Buyouts' conference by Osney media, June 2007.

38 Accounting Standards Board FRS 17 Amendment December 2006, page 4, paragraph 5.

39 Financial Reporting Review Panel: Report on the results of a review into defined benefit disclosures by companies under both IFRS and UK GAAP dated 2 August 2006 (pages 3 and 14). 
40 Accounting Standards Board FRS 17 Amendment December 2006, page 3, paragraph 4 .

41 The Pensions Act 2004, section 224(2)(a).

42 The Pensions Act 2004, section 224(2)(c).

43 The Pensions Act 2004, section 222(2).

44 The Pensions Regulator May 2007 Abandonment of defined benefit pension schemes - Guidance document - see www. thepensionsregulator.gov.uk.

45 The Pensions Act 1995 section 75.

46 The Pensions Regulator May 2007 Abandonment of defined benefit pension schemes - Guidance document - page 5, paragraphs 6-10.

47 The Pensions Regulator May 2007 Abandonment of defined benefit pension schemes - Guidance document - pages 7-15, paragraphs 21-66.
48 Prudential plc Analysis, June 2007 - from presentation by Tom Boardman of Prudential plc.

49 Aon Consulting Limited (a division of Aon Corporation) - 17 April 2007 - research involving a survey of 150 UK companies operating defined benefit pension schemes between November 2006 and February 2007 - see http://www.aon.com/uk/en/ about/media-centre/pension-buyout-market.jsp.

50 Aon Consulting Limited (a division of Aon Corporation) Comment by Paul Belok, Head of Closed Schemes at Aon Consulting 17th April, 2007 in Aon Media Centre speaking about research involving a survey of 150 UK companies operating defined benefit pension schemes between November 2006 and February 2007 also referred to in note above - see http://www.aon.com/uk/en/about/media-centre/pensionbuyout-market.jsp. 